\title{
ANALISIS PENGENDALIAN KUALITAS PRODUK TELUR ASIN PADA UD. SARI LUWIH DI DESA PADANG LUWIH
}

\author{
Angela Ayu Dewi Candrawati ${ }^{1}$ \\ I Nyoman Nurcaya ${ }^{2}$ \\ ${ }^{1,2}$ Fakultas Ekonomi Dan Bisnis Universitas Udayana (Unud), Bali, Indonesia \\ email: angeladewi2101@gmail.com ${ }^{1}$
}

\begin{abstract}
ABSTRAK
Kualitas yang baik dalam proses produksi, dengan standar yang telah ditentukan akan meminimalisir produk rusak. Penelitian dilakukan di UD. Sari Luwih merupakan perusahaan dibidang manufaktur dan dagang yang memproses dan menjual produk telur asin. Penelitian ini bertujuan untuk mengetahui sistem pengendalian kualitas proses produksi telur asin pada UD. Sari Luwih sudah optimal atau belum. Penelitian bersifat deskriptif dengan pendekatan kualitatif. Metode pengambilan sampel dengan teknik sensus. Data yang dipergunakan pada penelitian ini, merupakan data jumlah produk telur asin yang rusak pada periode Oktober s.d November 2019 dengan sampel jenuh sebanyak 37.500 butir telur. Teknik analisis yang digunakan yaitu pengendalian kualitas secara statistic (SQC) menggunakan Check sheet, Pchart, Fishbone diagram, dan Quality cost. Hasil analisis menggunakan P-chart menunjukan jumlah kerusakan produk yang berada diluar batas kendali dan memerlukan pengendalian lebih, sedangkan untuk biaya kualitas pada tahun 2019, biaya kualitas perusahaan secara aktual yaitu Rp. 21.210.696,89 lebih besar dari biaya kualitas secara optimum dimana biaya tersebut sebesar Rp. 17.389.652,10 ini menunjukan bahawa biaya pengendalian kualitas belum mencapai tingkat optimal.
\end{abstract}

Kata kunci: biaya kualitas; kualitas; pengendalian kualitas secara statistik; SQC

\begin{abstract}
Good quality in the production process, with predetermined standards will minimize damaged products. The study was conducted at UD. Sari Luwih is a manufacturing and trading company that processes and sells salted egg products. This study aims to determine the quality control system of salted egg production processes at UD. Sari Luwih is optimal or not. Research is descriptive with a qualitative approach. The sampling method is by census technique. The data used in this study, is the data on the number of damaged salted egg products in the period from October to November 2019 with a sample of 37,500 eggs saturated. The analysis technique used is statistical quality control (SQC) using Check sheets, P-charts, Fishbone diagrams, and Quality cost. The results of the analysis using the P-chart show the amount of product damage that is beyond the control limits and requires more control, whereas for quality costs in 2019, the company's actual cost of quality is Rp. 21,210,696.89 is greater than the optimum quality cost where the cost is Rp. 17,389,652.10 shows that the cost of quality control has not yet reached the optimal level.

Keywords: quality cost; quality; statistical quality control; SQC.
\end{abstract}




\section{PENDAHULUAN}

Peningkatan permintaan pasar terhadap produk yang berkualitas tinggi semakin meningkatkan tekanan dalam berproduksi. Banyak perusahaan terpaksa untuk mengubah praktik kualitas mereka dan mengembangkan cara yang lebih baik untuk memastikan pelanggan puas tidak hanya dengan produk, tetapi juga prosesnya (Abdul et al., 2017). Keberhasilan perusahaan dicermikan dari kesuksesan dalam pembuatan produk yang dapat memenuhi harapan konsumen. Pengendalian kualitas proses yang baik akan meminimalkan produk yang rusak.

Persoalan yang sering timbul pada proses produksi yang dapat mempengaruhi kualitas produk adalah adanya produk rusak. Diperlukan langkah atau usaha dalam memecahkan permasalahan tersebut supaya kualitas produk dapat terjaga dengan baik (Hariyanto, 2017). Meminimumkan produk rusak merupakan suatu usaha yang tidak dapat dilakukan sekali namun dilakukan secara terus-menerus dalam hal meningkatkan kualitas produk (Rachman, 2017). Meminimumkan produk rusak dapat dilakukan perusahaan dengan mengendalikan kualitas produk yang dihasilkan melalui banyak metode seperti metode DMAIC (Define, Measure, Analyze, Improve dan Control), Six Sigma dan Statistical Quality Control (SQC). SQC merupakan teknik yang banyak digunakan di industri manufaktur untuk meningkatkan kualitas produk dan produktivitas pekerja (Oguntunde et al., 2015). Menurut Joghee (2017) SQC adalah alat statistik populer untuk memantau kualitas proses produksi dan mendeteksi proses yang keluar dari kendali sedini mungkin.

Biaya kualitas berpengaruh signifikan terhadap peningkatan kualitas suatu produk (Meisella Ransun et al., 2016). Menurut Ayach (2019) biaya kualitas merupakan bagian yang signifikan maka menjadi keharusan bagi perusahaan untuk mengelola dan memantau biaya terkait kualitas. Perusahaan dapat membuat keputusan untuk meningkatkan biaya pencegahan dan penilaian dan mengurangi biaya kegagalan internal dan eksternal agar lebih kompetitif di pasar (Moschidis et $a l ., 2018)$ dan Plewa dan Kaiser (2016).

Pengendalian kualitas dengan metode SQC telah banyak diteliti sebelumnya seperti Widiaswanti (2014), (Hossein et al., 2014), Jarrett (2014), Keller et al. (2015), Veiga et al. (2016), Ayu Ningsih dkk. (2016), Tanjaya (2017), Hariyanto (2017), Rachman (2017), Elmas (2017) Faiq dkk. (2018), Sari dan Purnawati (2018), Westgard et al. (2018), Vicentin et al. (2018), Yusuf dan Ahyadi (2019), Lim dan Azharman (2019) Sanusi dkk. (2019) dan Hairiyah dkk. (2019). Menurut Sari dan Purnawati (2018) melalui metode SQC menunjukkan hasil kerusakan produksi yang berada diluar batas kendali. Beberapa hasil penelitian menunjukan bahwa dengan menggunakan metode SQC telah menurunkan tingkat kerusakan pada saat produksi, ini ditunjukan oleh penelitian Sharma dan Kharub (2014), Azadeh et al. (2016) dan Solihudin dan Kusumah (2017).

Penelitian ini dilakukan di UD. Sari Luwih merupakan perusahaan yang berlokasi di Desa Padang Luwih, Kecamatan Kuta Utara, Badung, Bali, Indonesia. Perusahaan ini secara resmi berdiri pada tahun 2000, perusahaan ini bergerak dibidang usaha dagang sekaligus produksi telur asin. Pada awal berdirinya, perusahaan ini hanya bergerak dibidang usaha dagang dimana perusahaan hanya menjual telur asin ke warung-warung disekitar, tapi kemudian produksi telur asin ini membaik dan berniat melakukan produksi telur asin sendiri lalu menjualnya. 
Proses produksi telur asin dilakukan setiap hari untuk memenuhi permintaan konsumen. Perusahaan ini melaksanakan proses produksi pada pukul 09.00 WITA17.00 WITA, saat ini mempekerjakan sejumlah sembilan orang pekerja guna melaksanakan segala kegiatan produksi yang harus dilakukan perusahaan.

UD. Sari Luwih dengan ijin usaha nomor: 71/22-08/DPMPTSP/SIUP$\mathrm{K} / \mathrm{I} / 2018$, kini telah menjadi perusahaan dagang yang terpandang, khususnya di kabupaten Badung. Produk hasil produksi UD. Sari Luwih kini telah menyebar ke pasar tradisional, pasar modern dan untuk mengikuti perkembangan jaman dimana teknologi telah maju, UD. Sari Luwih juga menjual produknya dengan sistem online. Kesuksesan perusahaan dalam memasarkan produknya ini membuat perusahaan menjadi panutan dan motivasi bagi UMKM sejenis lainnya untuk dapat meraih kesuksesannya sendiri. Kesuksesan yang diperoleh perusahaan UD. Sari Luwih tidak terlepas dari usaha dan kerja keras ibu I Gusti Agung Ayu Diah Wiudari selaku pemilik usaha yang tidak pernah menyerah dan selalu ingin belajar untuk menjadi yang lebih baik lagi. Berdasarkan hasil observasi dan wawancara didapatkan bahwa setiap produksi 1500 telur asin sehari pada periode OktoberNovember 2019 akan ditemukan minimal rata-rata 100 telur asin yang rusak sekali proses produksi. Kriteria kerusakan produk seperti cangkang telur yang pecah saat produksi. Perusahaan harus mengeliminasi kerusakan tersebut untuk mencapai zero defect.

Produk yang rusak tersebut juga berpengaruh terhadap keuntungan yang diperoleh perusahaan karena biaya produksi yang dikeluarkan akan meningkat. Produk rusak tersebut tidak dapat diolah kembali sehingga akan menimbulkan kerugian. Artinya, jika perusahaan memproduksi produk dengan jumlah kerusakan yang terus meningkat maka akan mengurangi keuntungan perusahaan dikarenakan biaya produk per-unit meningkat.

\section{METODE PENELITIAN}

Desain penelitian adalah pendekatan kuantitatif yang berbentuk deskriptif, yaitu menjelaskan dan menguraikan terkait pelaksanaan pengendalian kualitas produk telur asin, faktor penyebab kerusakan pada produk yang diproduksi, serta solusi dalam mengatasi kendala-kendala pengendalian kualitas produk telur asin pada UD Sari Luwih.

Penelitian ini dilakukan di UD. Sari Luwih yang berada di Desa Padang Luwih, No.1, Dalung, Kuta utara, Badung, Bali, Indonesia Metode penentuan sampel yang digunakan pada penelitian ini adalah metode sensus. Metode sensus adalah penentuan sampel bila semua anggota populasi digunakan sebagai sampel. Penelitian dilaksanakan selama sebulan atau 25 hari kerja pada bulan Oktober 2019 sampai dengan November 2019

Objek penelitian dalam penelitian ini adalah pengendalian kualitas produksi produk telur asin pada UD. Sari Luwih Di Desa Padang Luwih. Variabel yang digunakan dalam penelitian ini adalah: 1) Jumlah Produksi; 2) Jumlah Produk Rusak; dan 3) Biaya Kualitas

Populasi dalam penelitian yaitu hasil produksi telur asin selama 25 hari kerja yaitu 37.500 butir telur asin. Penarikan sampel produksi telur asin selanjutnya 
diperiksa, dilakukan secara sampling jenuh yaitu semua anggota populasi menjadi bagian dari sampel.

Pemberi data atau informasi dalam penelitian ini dilakukan menggunakan metode purposive sample yaitu pemilihan pemberi informasi yang dilakukan secara sengaja berdasarkan tugas dan tanggung jawab dalam perusahaan. Pemberi informasi dalam penelitian ini sebanyak tiga orang yang terdiri dari pemilik perusahaan dan dua orang karyawan. Metode pengumpulan data yang digunakan dalam penelitian ini adalah sebagai berikut observasi dan wawancara.

Teknik analisis data dilakukan dengan menggunakan teknik pengendalian kualitas secara statistik dengan langkah-langkahnya adalah sebagai berikut: 1) Standar Kualitas Produk; 2) Mengumpulkan data produksi dan produk rusak (check sheet); 3) Membuat Peta Kendali P ( $P$ - chart); 4) Analisis Biaya Kualitas; dan 5) Membuat rekomendasi/ usulan perbaikan kualitas.

Penelitian ini menggunakan peta kendali p dengan batas kendali 1 sigma. Langkah dalam membuat peta kendali p sebagai berikut: (Heizer dan Rander, 2014:286):

$$
\overline{\mathrm{p}}=\frac{n p}{n}
$$

Keterangan:

np: jumlah gagal dalam sub grup

$\mathrm{n}$ : jumlah yang diperiksa dalam sub grup hari ke-i

Menghitung Garis Pusat atau Central Line (CL)

$$
C L=\bar{P}=\frac{\Sigma n p}{\Sigma n}
$$

Keterangan:

$\Sigma n p:$ jumlah total yang rusak

$\Sigma n$ : jumlah total yang diperiksa

Menghitung Batas Kendali Atas atau Upper Control Limit (UCL)

$$
U C L=\bar{P}+S D
$$

Dimana:

$$
S D=\sqrt{\frac{\bar{p}(1-\bar{p})}{n}}
$$

Keterangan:

SD: standr deviasi

$\bar{p}$ : rata-rata ketidak sesuaian produk

$n$ : jumlah sampel yang diperiksa

Menghitung Batas Kendali Bawah atau Lower Control Limit (LCL)

$$
L C L=\bar{P}-S D
$$

Dimana: 


$$
S D=\sqrt{\frac{\bar{p}(1-\bar{p})}{n}}
$$

Keterangan:

$\bar{p}$ : rata-rata ketidak sesuaian produk

$n$ : jumlah sampel yang diperiksa

Langkah selanjutnya membuat diagram sebab-akibat. Diagram dan analisis sebab akibat adalah cara yang sangat inovatif dan efisien untuk menyelesaikan masalah utama (Bose, 2012). Setelah berhasil dalam mengidentifikasikan faktor penyebab kerusakan dari produk yang di produksi lalu langkah selanjutnya yaitu memberikan solusi untuk mencegah dan memperbaiki masalah tersebut.

Analisis biaya kualitas ( $Q$ uality Cost) yang terdiri dari biaya pengawasan mutu (QCC), biaya jaminan mutu (QAC) dan total biaya kualitas (TQC) dengan rumus adalah sebagi berikut (Sari \& Purnawati, 2018).

Biaya Pengawasan Mutu (Quality Control Cost)

$$
Q C C=\frac{R . o}{q}
$$

Keterangan:

$Q C C$ : total biaya pengawasan mutu

$R$ : jumlah produksi selama periode

$o:$ biaya pengetesan

$q$ : jumlah produk rusak selama periode

Biaya Jaminan Mutu (Quality Assurance Cost)

$Q A C=c . q$

Keterangan:

$Q A C$ : total biaya jaminan mutu

$c$ : biaya jaminan mutu

$q:$ jumlah produk rusak selama periode

Biaya Atas Kualitas (Total Quality Cost)

$T Q C=Q C C+Q A C$

Keterangan:

$T Q C$ : total biaya atas mutu

$Q C C$ : total biaya pengawasan mutu

$Q A C$ : total biaya jaminan mutu

Langkah terakhir setelah diketahui penyebab terjadinya kerusakan produk, maka dapat disusun sebuah rekomendasi atau usulan tindakan untuk melakukan perbaikan kualitas produk.

\section{HASIL DAN PEMBAHASAN}

Berdasarkan Tabel 1. dapat diketahui bahwa dari 1.500 sempel telur asin yang diambil setiap harinya selama 25 hari kerja atau sebanyak 37.500 butir terdapat 1.511 butir telur yang rusak di mana keruakan 1.445 butir dari telur bebek atau bahan baku dan 66 butir dari telur asin atau produk jadinya. 
Tabel 1.

Standar Kualitas dan Jumlah Kerusakan Produk Telur Asin pada UD. Sari Luwih pada Bulan Oktober sampai dengan November 2019

\begin{tabular}{|c|c|c|c|c|c|c|c|c|c|c|c|}
\hline \multirow{2}{*}{$\begin{array}{l}\text { Hari } \\
\text { ke- }\end{array}$} & \multirow[t]{2}{*}{ Sampel } & \multicolumn{5}{|c|}{$\begin{array}{c}\text { Standar kualitas bahan baku } \\
\text { (kerusakan) }\end{array}$} & \multicolumn{4}{|c|}{$\begin{array}{l}\text { Standar Kualitas telur } \\
\text { asin (kerusakan) }\end{array}$} & \multirow[t]{2}{*}{$\begin{array}{c}\text { Jmlh } \\
\text { Kedua } \\
\text { standar }\end{array}$} \\
\hline & & KC & BT & RT & KT & jmlh & KC & WP & KT & jmlh & \\
\hline 1 & 1500 & 32 & 5 & 2 & 4 & 43 & 1 & 0 & 1 & 2 & 45 \\
\hline 2 & 1500 & 52 & 8 & 6 & 11 & 77 & 3 & 0 & 2 & 5 & 82 \\
\hline 3 & 1500 & 17 & 6 & 1 & 8 & 32 & 1 & 0 & 1 & 2 & 34 \\
\hline 4 & 1500 & 40 & 5 & 1 & 15 & 61 & 1 & 0 & 1 & 2 & 63 \\
\hline 5 & 1500 & 25 & 2 & 0 & 13 & 40 & 2 & 0 & 2 & 4 & 44 \\
\hline 6 & 1500 & 34 & 7 & 0 & 7 & 48 & 1 & 0 & 1 & 2 & 50 \\
\hline 7 & 1500 & 55 & 8 & 0 & 9 & 72 & 3 & 0 & 1 & 4 & 76 \\
\hline 8 & 1500 & 40 & 5 & 3 & 13 & 61 & 3 & 0 & 1 & 4 & 65 \\
\hline 9 & 1500 & 33 & 5 & 7 & 13 & 58 & 1 & 0 & 1 & 2 & 60 \\
\hline 10 & 1500 & 54 & 2 & 0 & 16 & 72 & 1 & 0 & 2 & 3 & 75 \\
\hline 11 & 1500 & 37 & 4 & 3 & 6 & 50 & 3 & 0 & 1 & 4 & 54 \\
\hline 12 & 1500 & 28 & 6 & 1 & 11 & 46 & 1 & 0 & 2 & 3 & 49 \\
\hline 13 & 1500 & 19 & 9 & 1 & 9 & 38 & 1 & 0 & 2 & 3 & 41 \\
\hline 14 & 1500 & 41 & 3 & 0 & 4 & 48 & 1 & 0 & 1 & 2 & 50 \\
\hline 15 & 1500 & 36 & 3 & 7 & 15 & 61 & 1 & 0 & 1 & 2 & 63 \\
\hline 16 & 1500 & 52 & 4 & 2 & 11 & 69 & 1 & 0 & 1 & 2 & 71 \\
\hline 17 & 1500 & 61 & 8 & 2 & 5 & 76 & 1 & 0 & 2 & 3 & 79 \\
\hline 18 & 1500 & 57 & 6 & 3 & 9 & 75 & 0 & 0 & 1 & 1 & 76 \\
\hline 19 & 1500 & 42 & 2 & 2 & 12 & 58 & 0 & 0 & 1 & 1 & 59 \\
\hline 20 & 1500 & 29 & 2 & 1 & 9 & 41 & 2 & 0 & 1 & 3 & 44 \\
\hline 21 & 1500 & 30 & 4 & 3 & 15 & 52 & 3 & 0 & 1 & 4 & 56 \\
\hline 22 & 1500 & 52 & 8 & 1 & 8 & 69 & 1 & 0 & 2 & 3 & 72 \\
\hline 23 & 1500 & 47 & 4 & 5 & 4 & 60 & 0 & 0 & 2 & 2 & 62 \\
\hline 24 & 1500 & 48 & 7 & 0 & 13 & 68 & 0 & 0 & 1 & 1 & 69 \\
\hline 25 & 1500 & 57 & 6 & 0 & 7 & 70 & 1 & 0 & 1 & 2 & 72 \\
\hline $\mathbf{J m l}$ & 37500 & 1018 & 129 & 51 & 247 & 1445 & 33 & $\mathbf{0}$ & 33 & 66 & 1511 \\
\hline
\end{tabular}


Terdapat tujuh kriteria yang dibagi menjadi dua sub bagian yaitu dari bahan baku dan dari hasil produksi di mana kriteria-kriteria tersebut seperti cangkang telur bebek yang retak, telur yang busuk atau tidak segar, bentuk telur bebek tidak lonjong dan rongga telur yang besar sedangkan untuk produk jadi terdiri dari cangkang telur asin yang rusak, berbau busuk atau tidak segar dan waktu pengasinan untuk telur dibawah dua minggu.

Dari dua sub bagian kriteria-kriteria yang terlihat dengan kerusakan tertinggi yaitu dari kulit cangkang telur bebek yang retak yaitu sebanyak 1.018 dari total 37.500 telur yang di observasi selama 25 hari kerja. Terdapat 129 butir telur bebek rusak yang tidak memiliki bentuk lonjong. Terdapat 51 butir telur bebek yang rusak akibat rongga telur yang besar. Sebanyak 247 butir telur bebek yang tidak segar. Dari segi telur asin atau telur bebek yang sudah melalui tahap pengasinan terdapat 33 butir telur asin yang retak setalah proses pengasinan, dan 33 butir telur asin yang tidak segar.

Keterangan:

$\begin{array}{ll}\text { KC } & \text { : Kulit Cangkang } \\ \text { BT } & \text { : Bentuk Telur } \\ \text { RT } & \text { : Rongga Telur } \\ \text { KT } & \text { : Kesegaran Telur } \\ \text { KC } & \text { : Kulit Cangkang } \\ \text { WP } & \text { : Waktu Pengasinan } \\ \text { KT } & \text { : Kesegaran Telur }\end{array}$

Tabel 2.

Batas Kendali Keruskan Produk Telur Asin UD. Sari Luwih pada Bulan Oktober s.d November 2019

\begin{tabular}{lll}
\hline Uraian & & Jumlah \\
\hline Jumlah sampel produksi (butir) & & 37.500 \\
jumlah kerusakan produk (butir) & & 1.511 \\
& CL & 0.040 \\
Batas Kendali & UCL & 0.045 \\
& LCL & 0.035 \\
\hline
\end{tabular}

Sumber: Data Observasi 2019

Agar lebih jelas dapat dilihat dalam rincian perhitungan untuk mendapatkan Central Line (CL), Upper Control Line (UCL), Lower Control Line (LCL) sebagai berikut:

1) Menghitung Central Line (CL)

$$
\begin{aligned}
C L=\bar{P} & =\frac{\Sigma n p}{\Sigma n} \\
& =\frac{1511}{37500} \\
& =0,04
\end{aligned}
$$

2) Menghitung Upper Control Limit (UCL) 


$$
\begin{aligned}
S D & =\sqrt{\frac{\bar{p}(1-\bar{p})}{n}} \\
& =\sqrt{\frac{0,04(1-0,04)}{1500}} \\
& =0,005 \\
U C L & =\bar{P}+S D \\
& =0,04+0,005 \\
& =0,045
\end{aligned}
$$

3) Menghitung Lower Control Limit (LCL)

$$
\begin{aligned}
L C L & =\bar{P}-S D \\
& =0,04-0,005 \\
& =0,035
\end{aligned}
$$

Setelah mendapatkan hasil dari perhitungan CL, UCL dan LCL maka selanjutnya menbuat diagram P (P-chart) yang disajikan pada Gambar 1.

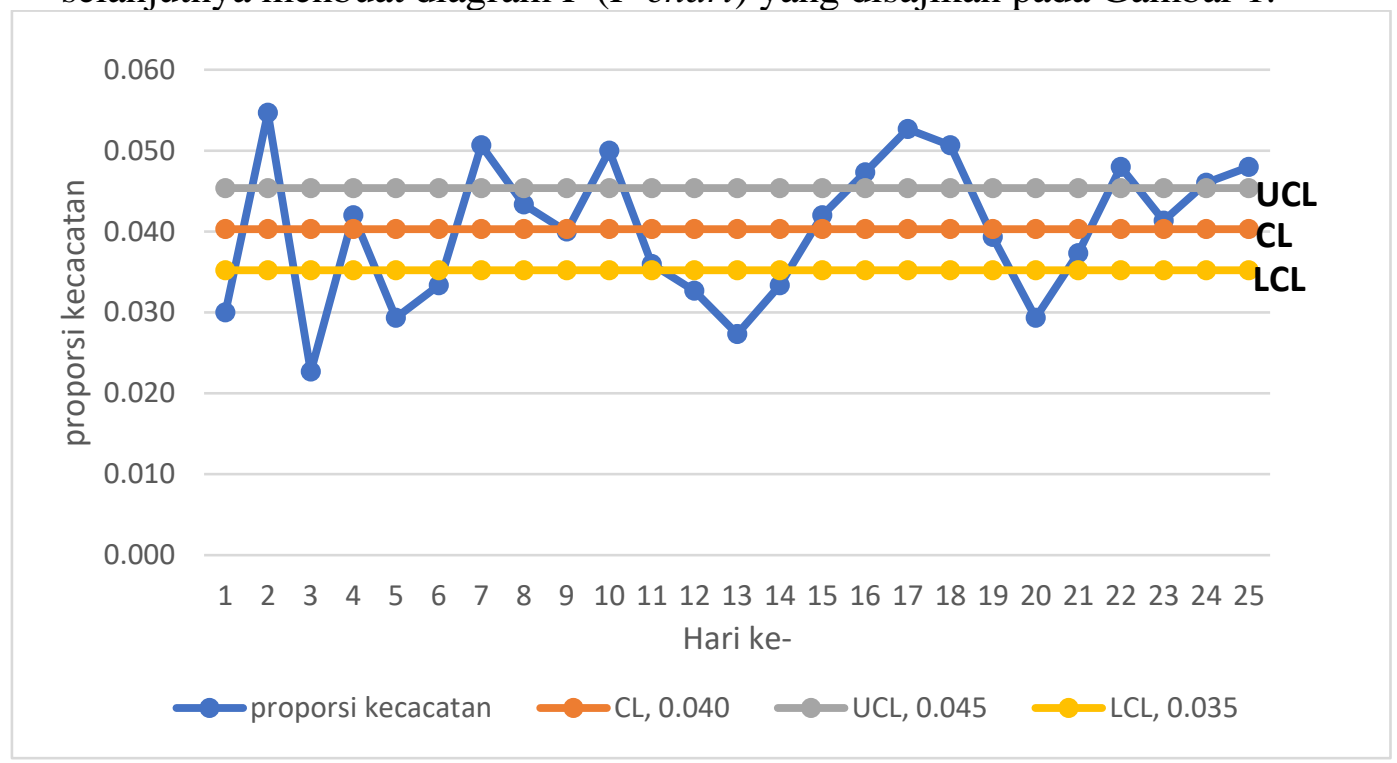

\section{Gambar 1. Diagram P Produk Telur Asin pada Bulan Oktober s.d} November 2019

Sumber: Data diolah, 2019

Berdasarkan Gambar 1. dapat dilihat bahwa masih banyak proses yang diluar batas kendali, ini berarti bahwa pengendalian kualitas proses produk telur asin pada UD. Sari Luwih masih kurang dan butuh perbaikan.

Berdasarkan hasil anlasis, jumlah produk cacat yang terdapat pada Tabel 1. diketahui bahwa, jumlah produk cacat sejumlah 1511 butir yang teridiri dari 1018 butir cangkang telur bebek yang rusak, 129 butir bentuk telur bebek yang tidak sesuai standar, 51 butir rongga pada telur bebek yang tidak sesuai standar, 247 butir 
telur bebek yang tidak segar, sedangkan untuk telur asin atau produk jadi 33 telur asin yang rusak pada cangkangnya dan 33 telur asin yang tidak segar.

Enam jenis kerusakan akan dianalisis menggunakan fishbone diagram. Kerusakan pertama cangkang telur bebek digambarkan sebagai berikut. Pada Gambar 2. memperlihatkan bahwa kerusakan produk telur bebek yang cangkang telurnya rusak disebabkan oleh beberapa faktor penyebab, yaitu faktor man dan faktor methode. Faktor pertama yaitu faktor man karena, proses pernyortiran telur bebek dilakukan secara manual maka kadang pekerja kurang berhati-hati saat meletakan telur, serta saat pernyortiran kurang teliti meemilih telur bebek. Dikarenakan bahan baku telur bebek ini datang dari luar pulau yaitu Pulau Jawa, jadi beberapa telur ada yang sudah mulai retak saat sampai di tempat produksi, kurang teliti pekerja dalam pernyortiran tersebut yaitu saat pekerja tetap meloloskan telur yang sudah mulai retak tersebut. Faktor selanjutnya yaitu faktor methode, apabila pekerja tidak mengikuti SOP (standar kerja) yang berlaku maka akan menyebabkan kerusakan pada telur seperti tidak meletakan telur ditempat yang telah ditempatkan dalam SOP.

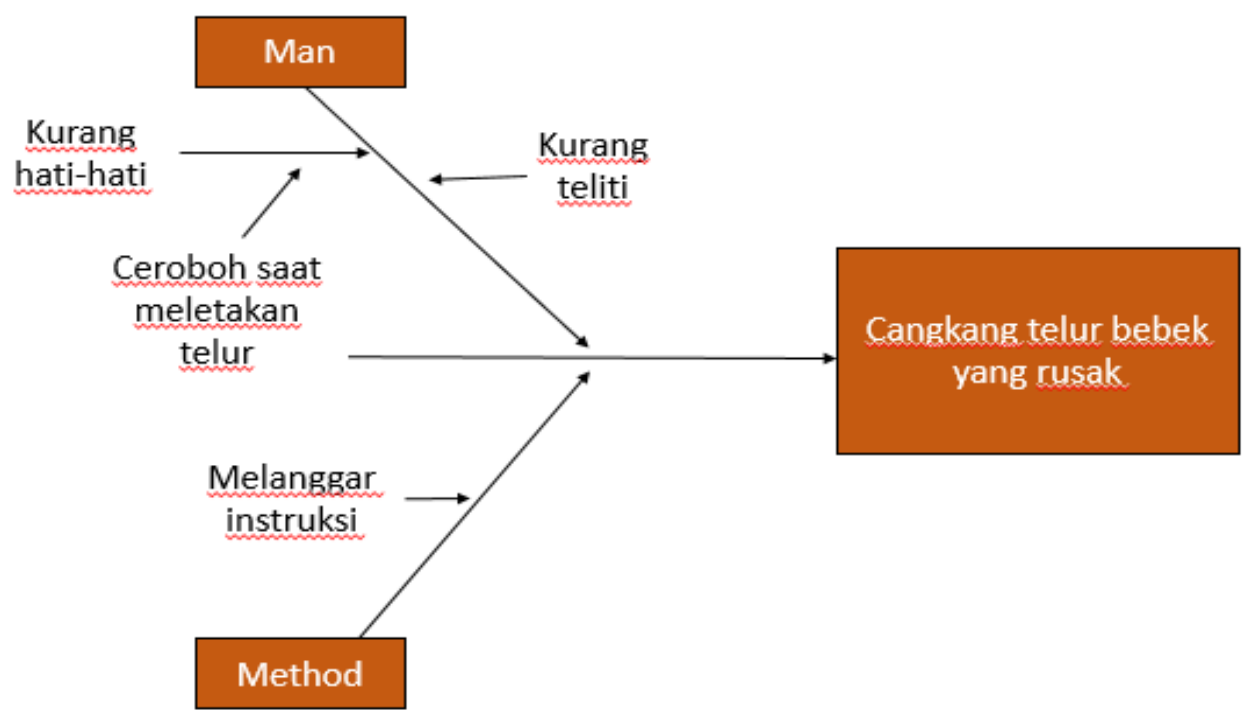

Gambar 2. Fishbone Diagram Produk Rusak Cangkang Telur Bebek Sumber: Data diolah, 2019

Kerusakan kedua yaitu bentuk telur bebek yang tidak sesuai dengan standar yang telah ditetapkan. Standar kualitas tersebut bentuk telur bebek lonjong. Diagram sebab akibat ditunjukan pada Gambar 3.

Pada Gambar 3. memperlihatkan penyebab dari bentuk telur bebek yang tidak sesuai dengan standar kriteria produk yaitu disebabkan oleh faktor bahan baku. Faktor ini yaitu faktor bahan baku yang datang dari pemasok telur bebek sudah dibawah standar kualitas yang ditetapkan, tidak lonjong seperti telur bebek kebanyakan. 


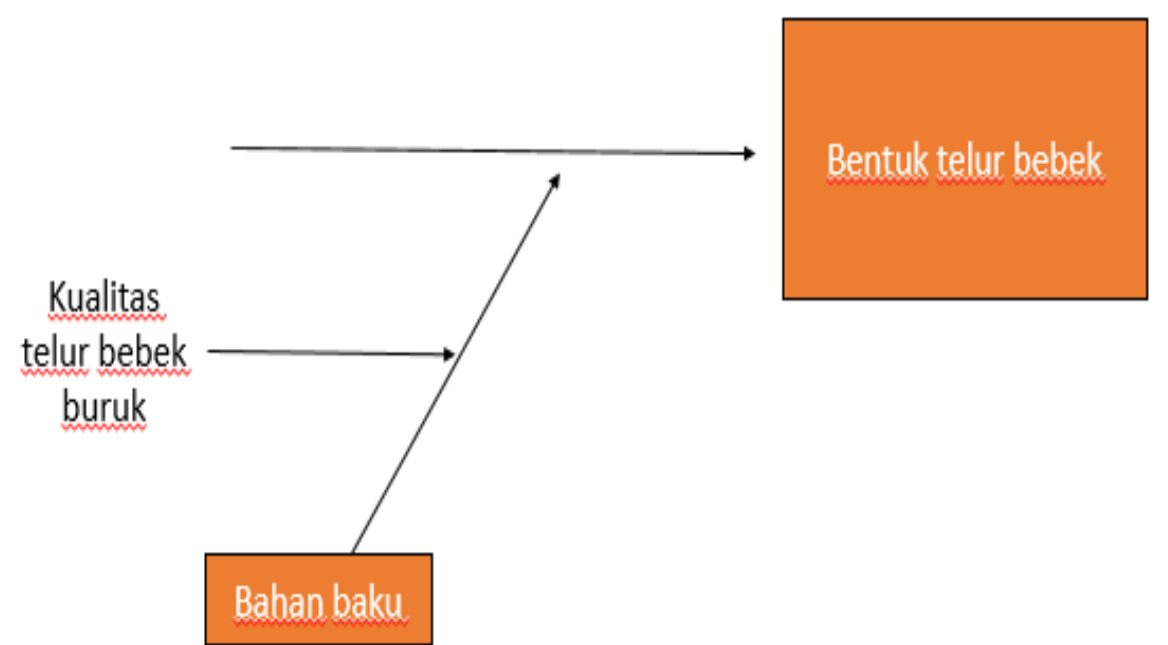

Gambar 3.Fishbone Diagram Produk Rusak Pada Bentuk Telur Bebek Sumber: Data diolah, 2019

Pada Gambar 4. memperlihatkan penyebab dari bentuk telur bebek yang tidak sesuai dengan standar kriteria produk yaitu disebabkan oleh faktor bahan baku. Kerusakan yaitu ukuran pada rongga telur bebek. Diagram sebab akibat ditunjukan pada Gambar 4. Pada Gambar 4. menunjukan penyebab ukuran pada rongga telur bebek yang tidak memenuhi standar kualitas yaitu tidak sesuai ukuran. Pada pernyortiran telur bebek ini dilakukan oleh pekerja yang sudah ahli dibidang ini, maka pekerja tersebut bahwa telur bebek tidak memenuhi standar kriteria. Faktor terjadinya kerusakan yaitu faktor dari bahan baku, bahwa ini tidak dapat dihindari dikarenakan kita menerima bahan baku yang dikirim dari pemasok dan dilakukan pernyortiran kembali dan menemukan bahwa beberapa telur tidak memeuhi standar kualitas yang ditetapkan.

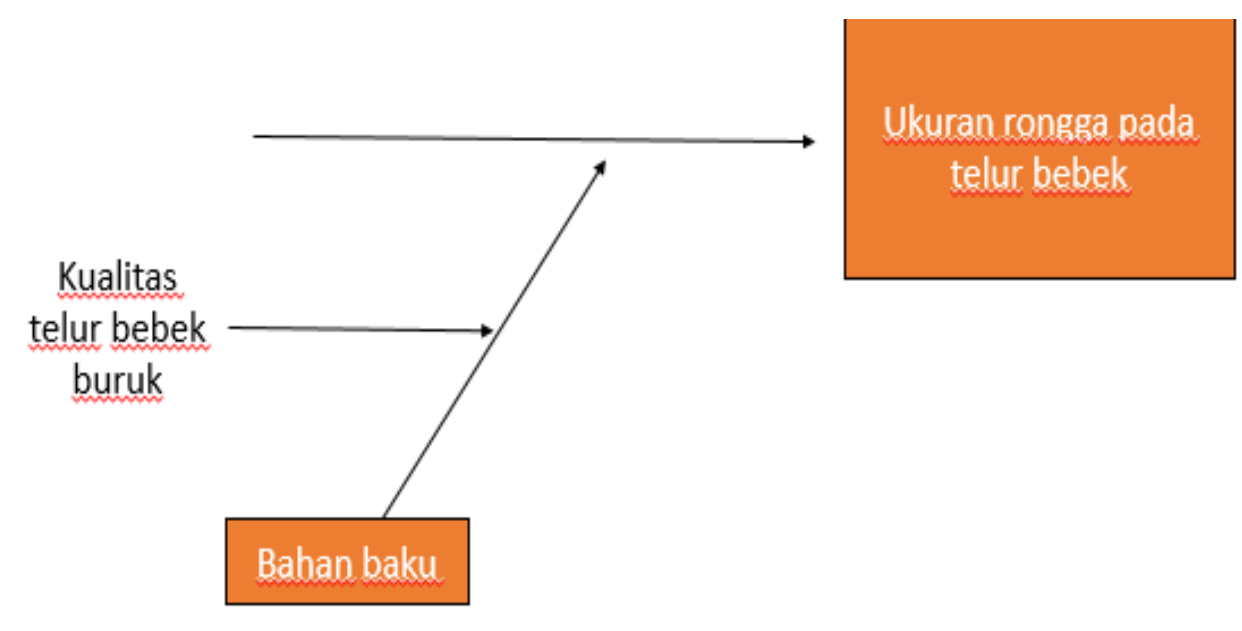

Gambar 4. Fishbone Diagram Produk Rusak Ukuran Pada Telur

Sumber: Data diolah, 2019

Bebek 
Pada gambar 5. memperlihatkan penyebab dari bentuk telur bebek yang tidak sesuai dengan standar kriteria produk yaitu disebabkan oleh faktor bahan baku, lingkungan dan manusia. Kerusakan yaitu kesegaran telur bebek. Diagram sebab akibat ditunjukan pada Gambar 5. Gambar 5. menunjukan penyebab kerusakan yang terjadi pada kesegaran telur bebek. Faktor yang mempengaruhi yaitu faktor manusia, faktor lingkungan dan faktor bahan baku. Faktor manusia, dikarenakan pekerja kurang hati-hati saat penyortiran maka telur bebek yang memang sudah dari pemasok tidak berkualitas baik kelewat dan akhirnya terjadi permasalahan saat di hasilnya yaitu di telur asin.

Pekerja juga tidak berhati-hati dalam meletakan telur yang sudah lewat proses penyortiran dikarenakan faktor kedua yaitu faktor lingkungan yang dipengaruhi oleh suhu dan cuaca yang berubah bisa mempercepat proses telur bebek menjadi tidak segar. Oleh karena itu, tempat telur diletakan saat setelah melewati proses penyortiran itu penting untuk menjaga kesegaran telur bebek.

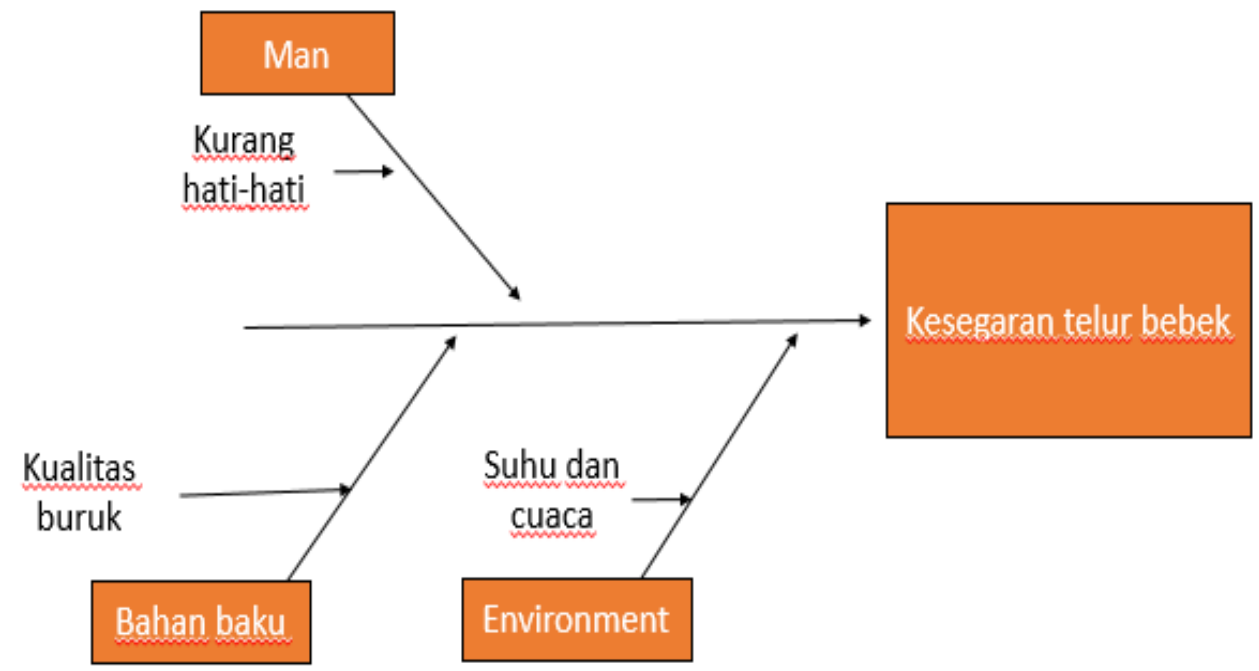

\section{Gambar 5. Fishbone Diagram Produk Rusak Pada Kesegaran Telur Bebek}

Sumber: Data diolah, 2019

Pada Gambar 6. memperlihatkan penyebab dari bentuk telur bebek yang tidak sesuai dengan standar kriteria produk yaitu disebabkan oleh faktor manusia dan metode. Pada Gambar 6. memperlihatkan penyebab dari bentuk telur bebek yang tidak sesuai dengan standar kriteria produk yaitu disebabkan oleh faktor metode dan manusia. Kerusakan yaitu cangkang telur asin, diagram sebab-akibat digambrakan pada Gambar 6. Pada Gambar 6. memperlihatkan penyebab dari kerusakan yang terjadi pada kulit cangkang telur asin yang telah di produksi. Penyebab kerusakan yaitu faktor man dan faktor methode.

Pada faktor manusia, kurang hati-hatinya pekerja saat meletakan telur yang sudah di proses, dan saat telur diproses menyebabkan kerusakan pada cangkang telur. Faktor selanjutnya yaitu faktor metode, tidak mengikuti sesuai instruksi 
standar yang telah ditetapkan merupakan salah satu faktor penyebab kerusakan produk telur asin

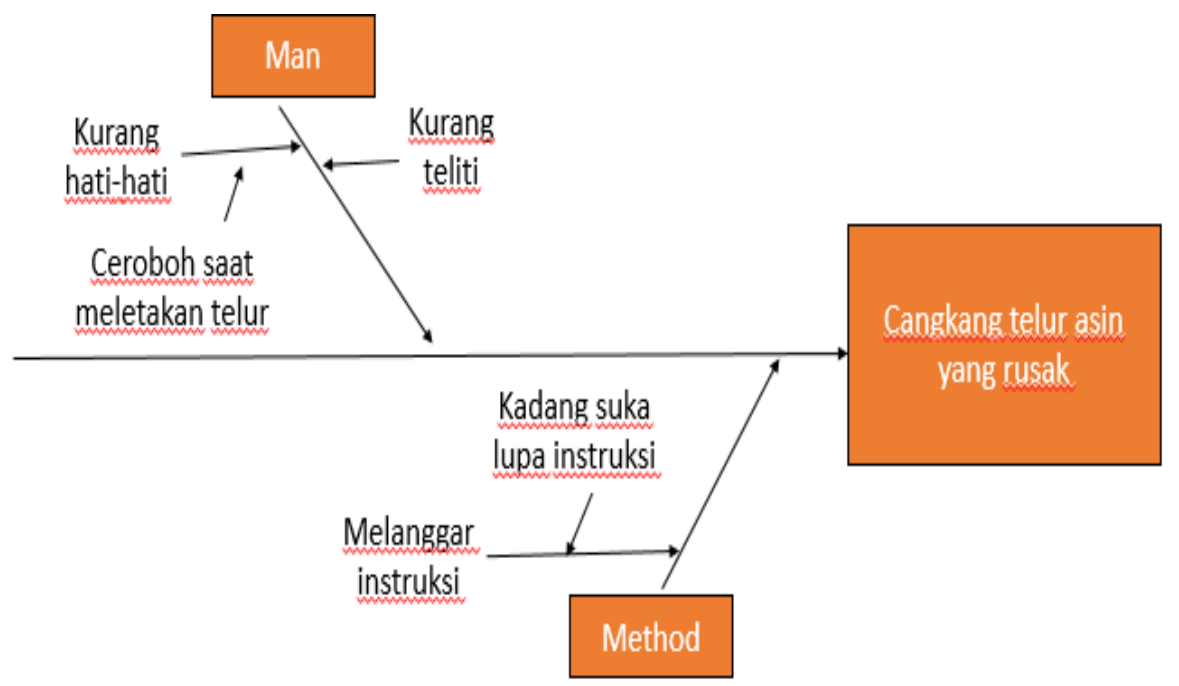

\section{Gambar 6. Fishbone Diagram Produk Rusak Cangkang Telur Asin}

Sumber: Data diolah, 2019

Pada Gambar 7. memperlihatkan penyebab dari bentuk telur bebek yang tidak sesuai dengan standar kriteria produk yaitu disebabkan oleh faktor manusia, meotde dan lingkungan. Kerusakan yaitu kesegaran telur asin. Diagram sebab akibat ditujukan pada Gambar 7. Pada Gambar 7. menggambarkan penyebab keruskan pada kesegaran telur asin. Kerusakan tersebut dipicu oleh beberapa faktor yaitu faktor manusia, faktor lingkungan dan faktor dari metode. Pada faktor manusia, kurangnya hati-hati dalam meletakan telur setalah di proses menjadi salah satu penyebab kerusakan kesegaran telur asin.

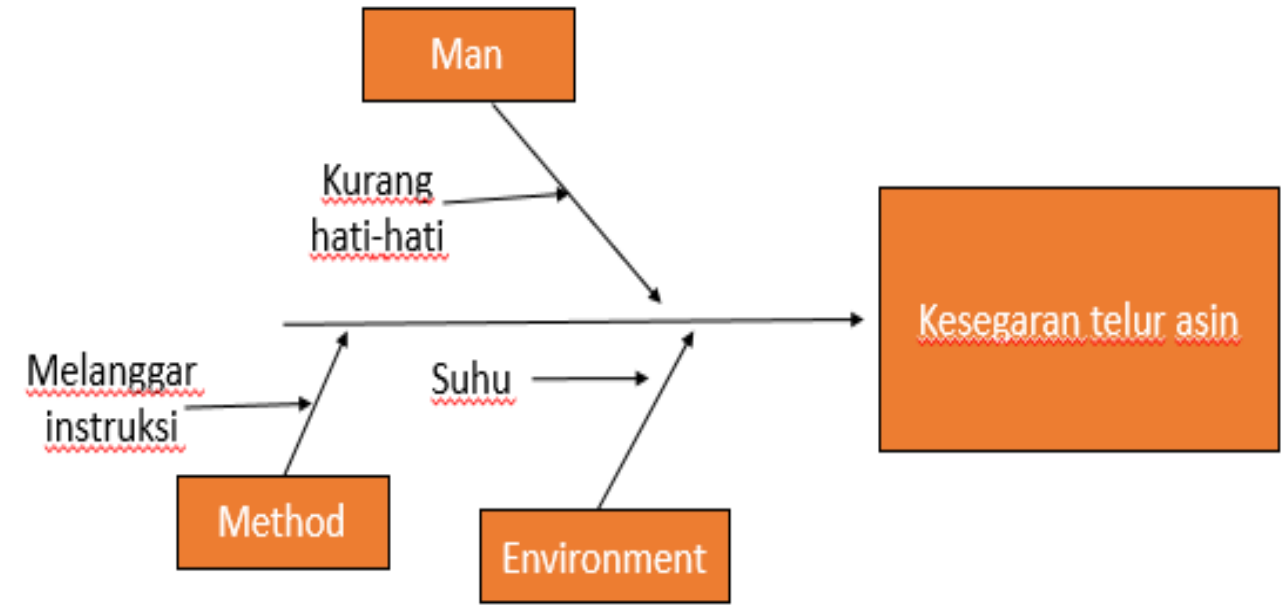

Gambar 7. Fishbone Diagram Produk Rusak Pada Kesegaran Telur Asin Sumber: Data diolah, 2019

Pada faktor lingkungan suhu juga menjadi penyebab kerusakan kesegaran, dimana semakin tinggi suhu dalam ruangan tersebut semakin cepat kualitas telur 
menurun. Maka dianjurkan menyimpan telur ditempat yang mempunyai suhu yang rendah. Pada faktor metode dimana para pegawai kerap lupa menaruh telur ditempat yang telah ditetapkan sehingga kesegaran telur asin tidak terjaga dengan baik dan menyebabkan telur menjadi rusak.

Pengawasan kualitas pada peta kendali yang sebelumnya pada UD. Sari Luwih masih kurang, sehingga memerlukan pengawasan yang lebih dan tentunya memerlukan biaya yang lebih, namun untuk mengetahui bahwa pengendalian diatas sudah optimal, maka diperlukan analisis terkait biaya kualitas. Hal yang harus ditentukan pertama kali adalah jumlah produk yang rusaknya terendah, kemudian dilanjutkan dengan mencari biaya pengawasan kualitas, biaya jaminan kualitas serta total biaya kualitas terendah sehingga nantinya biaya kualitas optimum dapat dicapai. Biaya pengawasan terdiri atas:

Biaya perawatan bahan baku Rp.150.000/bulan

Biaya pemeliharaan mesin peralatan (mesin) Rp.100.000/bulan

Rp.250.000/bulan

Biaya jaminan kualitas merupakan biaya yang dikeluarkan oleh UD. Sari Luwih untuk menjaga agar kualitas produk yang dihasilkan terjamin, seperti biaya pengecekan produk. Biaya yang dikeluarkan Rp.3.000/ hari. Untuk dapat menghitung biaya aktual, maka pertama melakukan perhitungan mengenai biaya pengawasan. Perhitungan mengenai biaya pengawasan yaitu (1) Jumlah produksi tekur asin ( R ) selama 1 tahun x 37500 butir= 450.000 butir; (2) Biaya perawatan bahan baku sebelum memulai diproduksi selama 1 tahun xRp.150.000$=$ Rp.1.800.000; (3) Biaya tenaga kerja untuk mengawasi kualitas selama 1 tahun $\mathrm{x}$ Rp.1.250.000 (Rp.50.000x25hari kerja) = Rp.15.000.000; (4) Jumlah kegiatan pengendalian kualitas rata-rata dilakukan 25 hari kerja selama satu bulan, maka selama setahun 25x $12=300$ kali. Sehingga diketahui biaya pengetesan (o) adalah:

$$
o=\frac{1.800 .000+15.000 .000}{300}=56.000
$$

Sehingga biaya pengawasan kualitas (QCC)

$$
\text { 4) } \begin{aligned}
& \text { QCC }=\frac{R . o}{q} \\
& =\frac{450.000 \times 56.000}{1.511} \\
& =R p .16 .677 .696,89
\end{aligned}
$$

Biaya jaminan kualitas (QAC)

$$
\text { 5) } \begin{aligned}
Q A C & =c . q \\
& =3000 \times 1511 \\
& =R p .4 .533 .000
\end{aligned}
$$

Total biaya atas kualitas

6) $T Q C=Q C C+Q A C$

$$
=R p \cdot 16.677 .696,89+R p \cdot 4.533 .000
$$




$$
=\operatorname{Rp} .21 .210 .696,89
$$

Perhitungan biaya kualitas optimum

Berdasarkan perhitungan biaya pengawasan kualitas, maka dapat ditentukan jumlah telur asin yang rusak yang menanggung biaya minimal $\left(\mathrm{q}^{*}\right)$ yaitu:

$$
\text { 7) } \begin{aligned}
q *= & \sqrt{\frac{R . o}{c}} \\
& =\sqrt{\frac{450.000 \times 56.000}{3000}} \\
& =2.898,275349 \text { butir telur asin. }
\end{aligned}
$$

Dengan demikian, baiaya kualitas yang harus ditanggung oleh UD. Sari Luwih dengan jumlah kerusakan optimum yaitu:

Biaya pengawasan kualitas (QCC)

$$
\text { 8) } \begin{aligned}
\text { QCC } *= & \frac{R . o}{q} \\
& =\frac{450.000 \times 56.000}{2.898,275349} \\
& =R p .8 .694 .826,048
\end{aligned}
$$

Biaya jaminan kualitas (QAC)

$$
\text { 9) } \begin{aligned}
Q A C *= & c . q \\
& =3000 x 52,91503 \\
& =R p .8 .694 .826,048
\end{aligned}
$$

Total biaya atas kualitas

$$
\text { 10) } \begin{aligned}
T Q C *= & Q C C+Q A C \\
& =8.694 .826,048+8.694 .826,048 \\
& =\operatorname{Rp} .17 .389 .652
\end{aligned}
$$

Perbandingan biaya kualitas aktual perusahaan dengan biaya kualitas optimum

Berdasarkan perhitungan jumlah kerusakan produk serta biaya-biaya atas kualitas aktual dan optimum, maka selanjutnya dapat diketahui perbandingan hasil dari perhitungan tersebut yang akan disajikan dalam tabel, yaitu:

Tabel 3.

Perbandingan Biaya Aktual Perusahaan dengan Biaya Optimum Perusahaan

\begin{tabular}{llll}
\hline Indikator & Aktual & Optimal & Selisih \\
\hline Jumlah Kerusakan (butir) & 1.511 & $2.898,28$ & $1.387,28$ \\
Biaya Pengawasan Kualitas (Rp) & $16.677 .696,89$ & $8.694 .826,05$ & $7.982 .870,84$ \\
Biaya Jaminan Kualitas (Rp) & 4.533 .000 & $8.694 .826,05$ & $4.161 .826,05$ \\
Total Biaya Kualitas (Rp) & $21.210 .696,89$ & $17.389 .652,10$ & $3.821 .044,79$ \\
\hline
\end{tabular}

Sumber: Data diolah, 2019 
Berdasarkan Tabel 3. dapat dilihat bahwa jumlah kerusakan aktual sebesar 1.511 butir telur lebih kecil dibandingkan jumlah batas kerusakan optimal yaitu sebesar 2.898,28 butir telur, namun total biaya kualitas sebesar Rp 21.210.696,89 lebih besar dibandingkan biaya kualitas optimum sebesar Rp 17.389.652,10, hal ini disebabkan karena biaya pengawasan kualitas aktual yang tinggi sebesar Rp 26.677.696,89 dibandingkan biaya pengawasan optimum sebesar Rp 8.694.826,05 sedangkan biaya jaminan kualitas aktual sebesar Rp 4.533.000 lebih kecil dibandingkan biaya jaminan kualitas optimum sebesar Rp 8.694.826,05 Selisih antara total biaya kualitas aktual dengan total biaya kualitas optimum sebesar Rp 3.821.044,79 menunjukkan belum optimalnya pengendalian kualitas yang dilakukan perusahaan, karena terlalu tinggi mengeluarkan biaya pengawasan kualitas sehingga dapat mengurangi keuntungan yang diperoleh perusahaan. Berdasarkan Tabel 3 jadi dapat dibuatkan grafik mengenai hubungan antara total biaya kualitas dan tingkat kerusakan produk telur asin yang dibebankan ke perusahaan yang dijelaskan pada Gambar 8 .

Gambar 8. menunjukan bahwa selama periode tahun 2019 jumlah kerusakan telur asin menunjukan angka 1.511 butir yang mana untuk menghasilkan kerusakan sebanyak itu perusahaan telah mengeluarkan biaya-biaya sebesar biaya pengawasan kualitas (CQQ)sebesar Rp.16.677.696,89, biaya jaminan kualitas (QAC) sebesar Rp. 4.533.000 sehingga total biaya kualitas (TQC) sebesar Rp. 21.210.696,89. Jika biaya tersebut dibandingkan dengan biaya kualitas optimum dimana biaya pengawasan kualitas pada titik optimum (CQQ*) sebesar Rp.8.694.826,05, biaya jaminan kualitas pada titik optimum (CAQ*) sebesar Rp. 8.694.826,05 sehingga biaya kualitas total pada titik optimum (TQC*) sebesar Rp.17.389.652,10. Dari analisis data tersebut dapat disimpulkan bahwa biaya pengawasan kualitas yang dilakukan masih kurang optimal yang dapat dilihat dari baiaya kualitas aktualnya lebih besar dari pada biaya kualitas optimal.

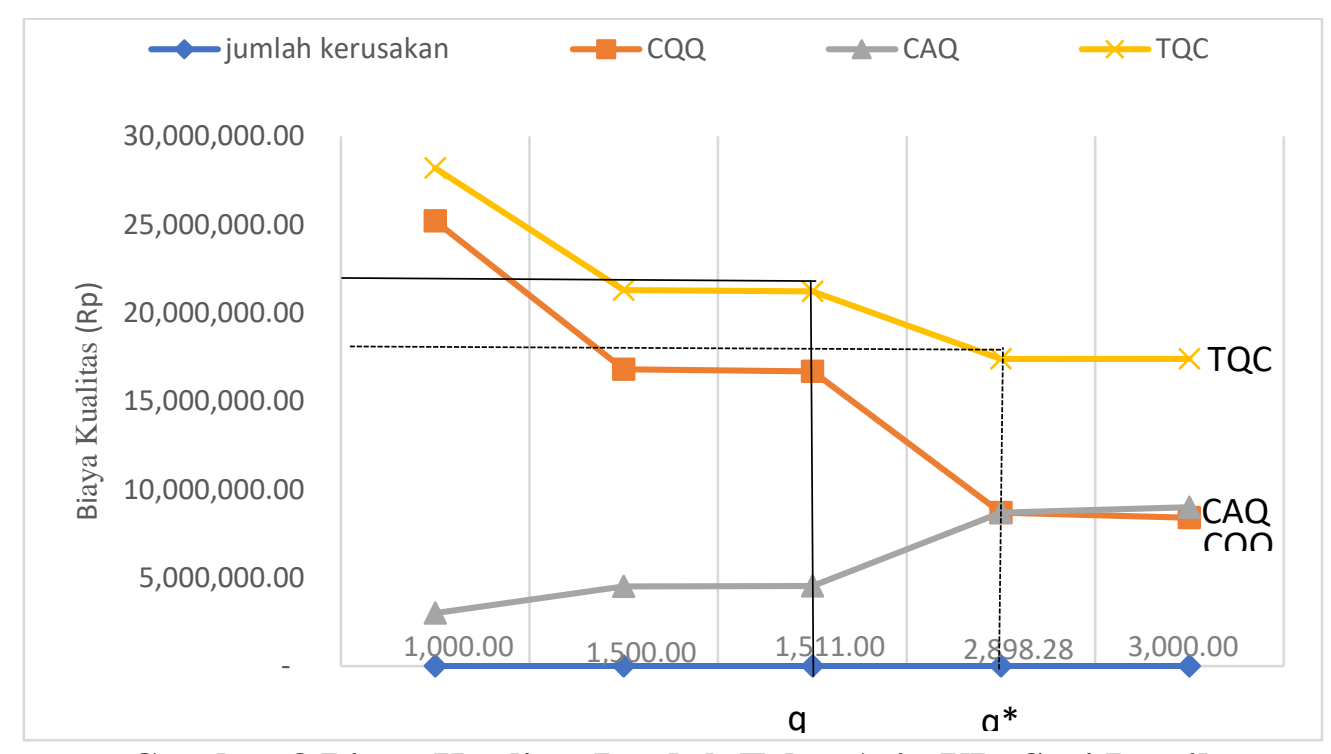

Gambar 8.Biaya Kualitas Produk Telur Asin UD. Sari Luwih Sumber: Data diolah, 2019 
Analisis perbaikan kualitas produk merupakan langkah selanjutnya setelah penyebab ternyadinya penyimpangan diketahui pada UD. Sari Luwih, untuk itu perlu menyusun suatu langkah perbaikan secara umum dalam upaya mengurangi tingkat kerusakan pada produk yang diproduksi. Beberapa upaya yang dapat dilakukan untuk mengurangi kerusakan pada telur asin di UD. Sari Luwih yaitu (1) Faktor manusia, perusahaan dapat memberikan sosialisasi secara rutin untuk meningkatkan pemaham karyawan terhadap proses produksi yang dilakukan. (2) Metode, perusahaan sebaiknya membuat dan menempelkan SOP ditempat-tempat tertentu. (3) Lingkungan, perusahaan sebaiknya membuat lingkungan tempat proses produksi dapat lebih bersih agar kesegaran telur tetap terjaga. (4) Material, perusahaan lebih memperjelas perjanjian dengan pemasok terkait ketentuan bahan baku dan memberikan sanksi apabila perjanjian tersebut tidak terlaksana

\section{SIMPULAN}

SQC atau Statistical Quality Control teknik statistik yang digunakan untuk mengendalikan kualitas dan memastikan agar suatu proses telah memenuhi standar kualitas yang telah ditetapkan. Pada peta kendali P di UD. Sari luwih dilihat masih banyak proses yang diluar batas kendali sehingga memerlukan pengendalian kualitas yang lebih seperti pada hari ke-1, ke-2, ke-3, ke-5, ke-6, ke-7, ke-9, ke-10, ke-12, ke-13, ke-14, ke-16, ke-17, ke-18, ke-20, ke-22, ke-24 dan ke-25 yang diluar batas kedali yang telah ditetapkan, batas-batas tersebut pada batas kendali atas (UCL) yaitu 0,045 dan batas kendali bawah (LCL) yaitu 0,035 yang ditunjukan pada Gambar 4.1. Adanya kerusakan produk telur asin yang ditemukan pada bulan Oktober-November 2019 tersebut harus dianalisis menggunkana fishbone diagram atau yang lebih dikenal sebagai diagram sebab-akibat. Fishbone diagram merupakan salah satu alat yang digunakan untuk mengetahui dan menemukan kemungkinan terjadinya kerusakan pada proses tersebut. Menggunakan fishbone diagram ini dapat diketahui bahwa secara garis besar penyebab kerusakan disebabkan oleh faktor man, method and environment.

Biaya kualitas yang dikeluarkan perusahaan selama proses produksi juga masih kurang optimum. Biaya-biaya kualitas tersebut yaitu biaya yang dikeluarkan perusahaan untuk menjaga kualitas agar sesuai standar yang telah ditetapkan perusahaan. Dalam perhitungan biaya kualitas perusahaan juga menghitung besaran biaya untuk pengawasan kualitas serta biaya jaminan kualitas terlebih dahulu, setalah itu akan didapatkan biaya total. Kedua biaya tersebut yaitu biaya pengawasan kualitas dan biaya jaminan kualitas akan mencapai titik temu dimana titik tersebut akan mengetahui jumlah produk rusak yang menanggung biaya, sehingga kualitas optimum akan dapat diketahui. Hasil analisis data dapat diketahui bahwa pada tahun 2019 jumlah produk yang rusak secara aktual yaitu sebanyak 1.511 butir telur, sedangkan jumlah optimal kerusakan produk yaitu sebanyak $2.898,28$ butir telur. Selisih kerusakan aktual dan optimal yang tinggi menyebabkan biaya pengendalian kualitas secara optimal sangat tinggi dan biaya jaminan kualitasnya sangat redah. Biaya pengendalian kualitas secara aktual (QCC) yaitu Rp. 16.677.696,89 dan biaya jaminan kualitas secara aktual (QAC) yaitu Rp. 4.533.000 sehingga biaya kualitas total (TQC) yang dikeluarkan perusahan yaitu Rp. 
21.210.696,89. Apabila dibandingkan denan biaya kualitas optimum, dimana biaya pengendalian kualitas secara optimum (QCC*) yaitu sebesar Rp.8.694.826,05 dan biaya jaminan kualitas secara optimum (QAC*) yaitu sebesar Rp.8.694.826,05 sehingga didapatkan baiaya kualitas total secara optimum (TQC*) yaitu sebesar Rp. 17.389.652,10. Analisis biaya tersebut dapat disimpulkan bahwa biaya pengendalian kualitas masih belum optimal dilihat dari biaya aktual yang lebih tinggi dibandingkan dengan biaya optimum perusahaan.

Saran yang bisa diberikan yaitu, perusahaan perlu perhatian kepada faktorfaktor yang menyebabkan kerusakan pada produk, adapaun hal-hal tersebut yaitu, (1) Faktor manusia, perusahaan dapat memberikan sosialisasi secara rutin untuk meningkatkan pemaham pegawai terhadap proses produksi yang dilakukan. (2) Faktor metode, perusahaan sebaiknya membuat dan menempelkan SOP ditempattempat tertentu. (3) Faktor lingkungan, perusahaan sebaiknya membuat lingkungan tempat proses produksi dapat lebih bersih agar kesegaran telur tetap terjaga. (4) Faktor material, perusahaan lebih memperjelas perjanjian dengan pemasok terkait ketentuan bahan baku dan memberikan sanksi apabila perjanjian tersebut tidak terlaksana.

\section{REFERENSI}

Abdul Halim Lim, S., Antony, J., He, Z., \& Arshed, N. (2017). Critical observations on the statistical process control implementation in the UK food industry: A survey. International Journal of Quality and Reliability Management, 34(5), 684-700. https://doi.org/10.1108/IJQRM-03-2015-0035

Ayach, L. (2019). Quality Cost Management in Moroccan Industrial Companies : Empirical Study. Journal of Industrial Engineering and Management, 12(1), 97-114.

Ayu Ningsih, N. K., Suamba, I. K., \& Raka Sarjana, I. D. G. (2016). Pengawasan Mutu pada Pengolahan Dodol Salak di CV Duta Gunung Salak. E-Jurnal Agribisnis Dan Agrowisata, 5(2), 399-407.

Azadeh, A., Ameli, M., Alisoltani, N., \& Haghighi, S. M. (2016). quality improvement in a radio therapy department. Quality \& Quantity, 50(6), 24692493. https://doi.org/10.1007/s11135-015-0272-3

Bose, T. K. (2012). Application Of Fishbone Analysis For Evaluating Supply Chain And Business Process- A Case Study On The St James Hospita. International Journal of Managing Value and Supply Chains, 3(2), 17-24. https://doi.org/10.5121/ijmvsc.2012.3202

Elmas, M. S. H. (2017). Pengendalian Kualitas Dengan Menggunakan Metode Statistical Quality Control (Sqc) Untuk Meminimumkan Produk Gagal Pada Toko Roti Barokah Bakery. Jurnal Penelitian Ilmu Ekonomi WIGA, 7, 15-22.

Faiq, A., Nurhajati, \& Hufron, M. (2018). Analisis Pengendalian Kualitas Proses Produksi Jenang Apel Dengan Metode Statistical Process Control (SPC) 
Untuk Menurunkan Tingkat Kerusakan Produk (Studi di CV. Bagus Agriseta Mandiri Batu). Riset Manajemen.

Hairiyah, N., Amalia, R. R., \& Luliyanti, E. (2019). Analisis Statistical Quality Control (SQC) pada Produksi Roti di Aremania Bakery. Industria: Jurnal Teknologi Dan Manajemen Agroindustri, 8(1), 41-48. https://doi.org/10.21776/ub.industria.2019.008.01.5

Hariyanto, M. A. (2017). Pengendalian Kualitas Produk Roti Tawar “ Della ” Menggunakan Metode Statistical Process Control. Simki-Economic, 01(05).

Heizer, J., \& Rander, B. (2014). Manajemen Operasi edisi 11 (Manajemen Keberlangsungan dan Rantai Pasokan). In Manajemen Operasi (11th ed., pp. 254-258). jakarta: Salemba Empat.

Hossein, M., Sabegh, Z., Mirzazadeh, A., \& Salehian, S. (2014). A Literature Review on the Fuzzy Control Chart; Classifications \& Analysis. International Journal of Supply and Operations Management, 1(2), 167-189.

Jarrett, J. E. (2014). The quality movement in hospital care. Quality \& Quantity: International Journal of Methodology, 48(November 2013), 3153-3167. https://doi.org/10.1007/s11135-013-9947-9

Joghee, R. (2017). Control chart for high-quality processes based on Six Sigma quality. International Journal of Quality \& Reliability Management, 34, 2-17. https://doi.org/10.1108/IJQRM-05-2015-0080

Keller, D. S., Stulberg, J. J., Lawrence, J. K., Samia, H., \& Delaney, C. P. (2015). Initiating statistical process control to improve quality outcomes in colorectal surgery. Surgical Endoscopy, 3559-3564. https://doi.org/10.1007/s00464015-4108-y

Lim, H., \& Azharman, Z. (2019). Analisis Pengendalian Kualitas Produk Pada Proses Perakitan Handphone Menggunakan Metode Statistical. Comasie Journal, 1(1).

Meisella Ransun, K., Paul Elia Saerang, D., \& L.Warongan, J. D. (2016). Pengaruh Biaya Kualitas Dan Biaya Produksi Terhadap Peningkatan Kualitas Produk Pada Trinity Percetakan Manado Influence the Cost of Quality and Production Cost on Product Quality Improvement At Trinity Percetakan Manado. Jurnal Berkala Ilmiah Efisiensi, 16(04), 79-90.

Moschidis, O., Chatzipetrou, E., \& Tsiotras, G. (2018). Quality costing and quality management maturity in Greece An exploratory multi-dimensional data analysis. International Journal of Productivity and Performance Management, 67(1), 171-191. https://doi.org/10.1108/IJPPM-08-2016-0152

Oguntunde, P. E., Odetunmibi, O. A., \& Oluwadare, O. O. (2015). A Comparative Study of the Use of Statistical Process Control in Monitoring Health Care Delivery. International Journal of Innovation and Scientific Research, 14(2), 154-158. 
Plewa, M., \& Kaiser, G. (2016). Is quality still free? International Journal of Quality \& Reliability Management, 33(9), 1270-1285. https://doi.org/10.1108/IJQRM-11-2014-0189

Rachman, R. (2017). Pengendalian Kualitas Produk Di Industri Garment Dengan Menggunakan Statistical Procces Control ( SPC ). Jurnal Informatika, 4(2), 174-182. Retrieved from http://ejournal.bsi.ac.id/ejurnal/index.php/ji/article/view/1970/pdf \%0A

Sanusi, Abdurahman, N. C., \& Setiawan, H. (2019). Pengendalian Kualitas Bordir Dengan Metode Statistical Quality Control. Jurnal Industri Kreatif(Jik), 3(2), 79. https://doi.org/10.36352/jik.v3i2.219

Sari, N. K. R., \& Purnawati, N. K. (2018). Analisis Pengendalian Kualitas Proses Produksi Pie Susu Pada Perusahaan Pie Susu Barong Di Kota Denpasar. EJurnal Manajemen Unud, 7(3), 1566-1594. https://doi.org/https://doi.org/10.24843/EJMUNUD.2018.v7.i03.p016 1566

Sharma, R., \& Kharub, M. (2014). Attaining competitive positioning through SPC - an experimental investigation from SME. Measuring Business Excellence, 18(4), 86-103. https://doi.org/10.1108/MBE-10-2013-0050

Solihudin, M., \& Kusumah, L. H. (2017). Analisis Pengendalian Kualitas Proses Produksi Dengan Metode Statistical Process Control ( Spc ) Di Pt . Surya Toto Indonesia, Tbk. Inovasi Dan Aplikasi Teknologi Industri, 1-8.

Tanjaya, Y. (2017). Analisis pengendalian kualitas produksi dalam upaya mengurangi tingkat kerusakan produk pada perusahaan jadoel bakery. PERFORMA: Jurnal Manajemen Dan Start-Up Bisnis, 2(2), 191-200.

Veiga, P., Mendes, L., \& Lourenço, L. (2016). A retrospective view of statistical quality control research and identification of emerging trends: a bibliometric analysis. Quality and Quantity, 50(2), 673-692. https://doi.org/10.1007/s11135-015-0170-8

Vicentin, D. S., Silva, B. B., Piccirillo, I., Bueno, F. C., \& Oprime, P. C. (2018). Monitoring process control chart with finite mixture probability distribution An application in manufacture industry. International Journal of Quality \& Reliability Management, 35(2), 335-353. https://doi.org/10.1108/IJQRM-112016-0196

Westgard, J. O., Bayat, H., \& Westgard, S. A. (2018). Planning Risk-Based SQC Schedules for Bracketed Operation of Continuous Production Analyzers. Clinical Chemistry, 64(2), 289-296. https://doi.org/10.1373/clinchem.2017.278291

Widiaswanti, E. (2014). Penggunaan Metode Statistical Quality Control ( Sqc ). Industri Inovatif, 4(2), 6-12.

Yusuf, S., \& Ahyadi, D. H. (2019). Peningkatan Kualitas Proses Assembly Line 1 Dengan Menggunakan Statistical Quality Control (SQC) Pada PT. X Quality 
E-Jurnal Manajemen, Vol. 9, No. 6, 2020 : 2332-2351

Improvement of Assembly Line 1 Process Using Quality Control Statistics (SQC) at PT. X. Sainstech, 29(2), 11-18. 